\title{
COOPETIÇÃO ENTRE CAFEICULTORES, COOPERATIVAS E ASSOCIAÇÕES: EVIDÊNCIAS NO MERCADO BRASILEIRO DE CAFÉS ESPECIAIS
}

\author{
Coopetition between coffee growers, cooperatives and associations: \\ evidences from Brazilian specialty coffee market
}

\begin{abstract}
RESUMO
Objetiva-se descrever como a competição e a colaboração simultâneas, fenômeno conhecido como coopetição, apresentam-se nos diversos níveis de interação sustentados pelos produtores de cafés especiais. Num contexto de interação dinâmica, heterogênea e intensa entre vários players, como é o caso das Indicações Geográficas (IGs) de café, cafeicultores se envolvem em relacionamentos interorganizacionais entre si, que, por meio de cooperativas e associações, permitem a coopetição se manifestar em níveis distintos. Dada a incipiência da abordagem coopetitiva no setor primário, a pesquisa qualitativa exploratória foi adotada para identificar e compreender melhor essa dinâmica de relacionamento. Os dados para a pesquisa foram coletados de entrevistas semiestruturadas com 20 atores que compõem as IGs da Alta Mogiana e da Região do Cerrado Mineiro: cafeicultores, cooperativas, instituições apoiadoras e gestores das associações. Os resultados foram separados em relacionamentos que promovem a competição e a cooperação, de forma a revelar a complexidade das suas práticas, num contexto que exige inovação em produto e processos. A descrição envolveu os níveis cafeicultor-cafeicultor, cooperativa-cooperativa e associação-associação, sendo que a necessidade de cooperação se mostrou onipresente no âmbito comercial, e a competição se manifestou em produtos, processos, serviços e finanças. Em IGs de café, a coopetição convive dentro do indivíduo, da empresa, da associação, da cooperativa, desde o nível intraorganizacional até o nível inter-redes, abrindo espaço para contribuições futuras.
\end{abstract}

Rodrigo Natal Duarte

Universidade de São Paulo - Faculdade de Economia, Administração e Contabilidade de Ribeirão Preto (USP/FEA-RP)

rodrigonatalduarte@gmail.com

Simone Vasconcelos Ribeiro Galina

Universidade de São Paulo - Faculdade de Economia, Administração e Contabilidade de Ribeirão Preto (USP/FEA-RP)

svgalina@usp.br

Recebido em: 10/09/2020. Aprovado em: 15/05/2021

Avaliado pelo sistema double-blind review

Avaliador científico: Elisa Reis Guimarães

DOI: $10.48142 / 2320211699$

\begin{abstract}
The purpose of this study is to describe how simultaneous competition and collaboration, a phenomenon known as coopetition, are presented at different levels of interaction sustained by specialty coffee producers. In a context of dynamics, intense and heterogeneous interaction between various players, such as the Geographical Indications (GIs) for coffee, coffee growers engage in interorganizational relationships with each other, and through cooperatives and associations, allowing coopetition to manifest itself at different levels. distinct. Given the incipient coopetitive approach in the primary sector, exploratory qualitative research was adopted to identify and better understand this relationship dynamics. Data for the research were collected from semi-structured interviews with 20 actors that make up the GIs of Alta Mogiana and the Cerrado Mineiro Region: coffee growers, cooperatives, supporting institutions and association managers. The results were separated into relationships that promote competition and cooperation, in order to reveal the complexity of their practices, in a context that requires product and process innovation. The description involved the levels of coffee grower-coffee grower, cooperative-cooperative and association-association, and the need for cooperation was omnipresent in the commercial sphere, and competition was manifested in products, processes, services and finance. In coffee GIs, coopetition coexists within the individual, the company, the association, the cooperative, from the intra-organizational level to the inter-network level, opening paths for future contributions.
\end{abstract}

Palavras-chave: Indicação Geográfica, Alta Mogiana, Cerrado Mineiro, PMEs, Comercialização.

Keywords: Geographical Indication, Alta Mogiana, Cerrado Mineiro, SMEs, Commercialization. 


\section{INTRODUÇÃO}

Embora a adaptação às mudanças externas e à inovação sejam fatores fundamentais para a longevidade das empresas (Engel \& Del-Palacio, 2011), muitas companhias não têm experiência ou recursos suficientes para reagir com rapidez ao cenário econômico em constante mudança ou para inovar em seus produtos, serviços e processos (Kraus, Schmid, \& Gast 2017). Por conta dessas limitações, empresas passaram a enxergar o relacionamento com outras empresas como um meio importante para lidar com dinâmicas de negócios cada vez mais aceleradas, em ambientes de maiores incertezas (Renna \& Argoneto, 2012).

Uma opção estratégica de relacionamento interorganizacional que vem ganhando espaço é a coopetição, definida por, "uma relação paradoxal entre dois ou mais atores, independentemente de estarem em relacionamentos horizontais ou verticais, envolvidos simultaneamente em interações cooperativas e competitivas" (Bengtsson \& Kock, 2014, p. 180). A literatura que explora a coopetição é relativamente farta quando foca em empresas de países desenvolvidos, já quando trata de empresas de países emergentes, a contribuição é bastante escassa (Devece, RibeiroSoriano \& Palacios-Marqués, 2019), bem como quando trata de pequenas e médias empresas (PMEs) (Bouncken, Gast, Kraus \& Bogers, 2015) e do setor primário.

Quando se refere às PMEs, por mais que a adoção da tecnologia lhes permita alcançar mercados globalizados, suas colaborações tendem a ser essencialmente locais (Levy, Loebbecke \& Powell, 2003). Um modelo representativo de governança local coletiva e que permite colocação competitiva global é o da Indicação Geográfica (IG), que visa proteger o patrimônio tradicional, o conhecimento do agricultor e os recursos ambientais associados a produtos com atributos especiais (Bowen, 2010). As IGs são ferramentas de Propriedade Intelectual, idealizadas, sobretudo, por produtores agroalimentares como mecanismos de inovação para ampliar a capacidade competitiva nos mercados (Niederle, Mascarenhas \& Wilkinson, 2017).

O café especial, que possui atributos de qualidade distinguíveis do café commodity ou convencional (Guimarães, Leme, De Rezende, Pereira \& Dos Santos, 2019), vem sendo explorado de forma crescente pelas IGs, conforme evidenciam os seis registros concedidos pelo Instituto Nacional de Propriedade Intelectual (INPI), entre os anos de 2019 e 2021, de doze existentes (INPI, 2021). Além do mais, o café possui o maior número de registros de IGs entre produtos do agronegócio no Brasil (INPI, 2021). Nessas IGs, cafeicultores comumente se envolvem em relacionamentos interorganizacionais em diversos níveis (Correa, Fante \& Dallabrida, 2016), formalizados por modelos jurídicos conhecidos de agremiação, como cooperativas e associações (Leme, Aguiar \& de Rezende, 2019), em busca de recursos que, de outra forma, seriam inacessíveis (Gnyawali \& Park, 2009; Morris, Kocak \& Özer, 2007).

A presença maciça do Estado e a ênfase na produção de um café convencional, até o final da década de 80, afastou o empreendedorismo do setor cafeeiro com impacto direto no estímulo à inovação (Saes, Jayo $\&$ da Silveira, 1997), reduzindo o número de produtos e promovendo comportamentos isomórficos entre os concorrentes (Mione, 2009). A melhoria da qualidade dos cafés regionais nacionais, a partir da década de 90 , deu-se a partir de esforços e investimentos dos próprios produtores, ao assumir os riscos da inovação produtiva e da formação de organizações locais, buscando fortalecimento, reconhecimento e melhores alternativas de comercialização (Singulano, 2015).

Fora das fronteiras nacionais, os cafeicultores encontram-se imersos em um mercado globalizado, cuja integração econômica vai além do comércio internacional de matérias-primas e produtos finais, para abranger uma produção centralmente coordenada, embora internacionalmente dispersa (Daviron \& Ponte, 2005). Essas esferas de relacionamento são compostas por pessoas físicas e jurídicas, instituições públicas e privadas atuando em diferentes escalas territoriais (Niederle, Mascarenhas \& Wilkinson, 2017), permitindo à coopetição manifestar-se em diversos níveis (Bengtsson \& Raza-Ullah, 2016).

Ainda que a prática da coopetição seja reconhecida e relevante no agronegócio, ela foi pouco explorada até agora (Leme et al., 2019; Queiroz, 2015). Como foi visto, cafeicultores envolvidos em projetos de IGs dispuseram-se a encarar a competição, sem abandonar necessariamente as práticas cooperativas, que os aproximaram. Dessa forma, a descrição das investidas competitivas e cooperativas dos atores envolvidos em uma IG cafeeira representa um bom ponto de partida para o estudo da coopetição no agronegócio.

Para tanto, realizou-se uma pesquisa qualitativa e exploratória em duas IGs cafeeiras, compostas por pequenos e médios cafeicultores, associações, cooperativas e instituições de apoio. Objetiva-se, consequentemente, descrever a dinâmica da coopetição entre os cafeicultores, associações e cooperativas a partir das suas práticas competitivas e cooperativas. 


\section{COOPETIÇÃO EM PMES DE PRODUTORES RURAIS}

A pesquisa de coopetição ainda se concentra principalmente em grandes empresas multinacionais influentes (Gnyawali \& Park, 2009) e apenas parcialmente em PMEs (Bouncken et al., 2015). No setor primário, a abordagem da coopetição ainda é muito pouco explorada; o convívio habitual dos produtores em modelos coletivos de organizações, como cooperativas e/ou associações, põe ênfase na cooperação, minimizando a prática da competição.

Não há consenso no que diz respeito a uma definição única de coopetição, exceto pelo reconhecimento de que o fenômeno consiste de ambas as lógicas cooperativas e competitivas, atuando simultaneamente. Isso ocorre principalmente porque a coopetição se materializa em vários níveis de interação, podendo ser diádicas, triádicas, intra-empresa ou em redes, sendo a coopetição em um nível distinta da coopetição em outro, a ponto de influenciar a própria definição empregada (Bengtsson \& Raza-Ullah, 2016), além de sugerir a sua desconexão com qualquer tipo específico de relacionamento (Czakon \& Rogalski, 2014).

No que diz respeito aos níveis de interação identificados por Bengtsson e Raza-Ullah (2016), a principal corrente das pesquisas, envolvendo a coopetição, concentra-se no nível interorganizacional, sobretudo as que exploram as relações diádicas horizontais, em que concorrentes diretos cooperam em algumas atividades enquanto competem em outras. A coopetição em redes é a segunda mais abrangente, embora seja a mais fragmentada, em que o ponto de vista adotado pode ser o do todo, ou o do "sistema", incluindo a análise de arranjos, regiões ou distritos. Já a coopetição intraorganizacional, cujas contribuições são as mais escassas, manifesta-se entre indivíduos, equipes, unidades funcionais ou unidades de negócios dentro da mesma organização.

As PMEs, por serem pequenas e fragmentadas, não têm uma "voz" forte no segmento em que atuam; a coopetição permite que elas desenvolvam uma "voz" comum, capaz de instituir normas relevantes (Gnyawali \& Park, 2009). Sendo as PMEs mais vulneráveis às forças ambientais, elas precisam administrar a falta de recursos de forma sustentável através do capital social de seus gestores, de forma a mobilizá-lo, para a implementação das estratégias de coopetição em suas empresas (Morris et al., 2007) e nas instituições às quais elas pertencem, a exemplo das cooperativas e associações.

A competitividade doméstica em setores relacionados oferece um fluxo de informações que acelera a taxa de inovação, em que empresas localizadas próximas umas das outras podem tirar proveito de linhas de comunicação curtas, fluxo rápido e constante de informações e uma troca contínua de ideias baseada em relações de trabalho estreitas (Porter, 1990), o que fundamenta as relações nas IGs.

A cafeicultura que crescia amparada por instrumentos de regulamentações e favores governamentais até o final da década de 80 , não desfrutava de qualquer estímulo para produzir qualidade: sua sustentação estava ancorada na lógica da produção em quantidade (Saes et al., 1997). A partir do início da década de 90, medidas de liberalização econômica impactaram a coordenação da cadeia de café, abrindo lacunas nos espaços decisórios que acabaram sendo preenchidas pelos estados e municípios, bem como por organizações privadas (Saes et al., 1997).

A Indicação Geográfica, prevista na Lei de Propriedade Industrial (Lei $\mathrm{n}^{\circ}$ 9.279/96), que permite aos produtores proteger um produto regional contra uso indevido, possibilita ainda aos pequenos negócios rurais a promoção de estratégias de conquista e posicionamento em diversos mercados domésticos e internacionais, estabelecendo um diferencial competitivo frente aos concorrentes a partir do desenvolvimento da liderança local (Mascarenhas \& Wilkinson, 2014) e a desejada aproximação entre produtores e compradores (Guimarães et al., 2019).

A interação entre as PMEs vizinhas facilita a atuação em mercados estrangeiros, reduzindo as limitações associadas ao seu tamanho e as dificuldades inerentes à consolidação da marca no mercado internacional, que podem gozar de prestígio no mercado doméstico, enquanto seu patrimônio e credibilidade são praticamente inexistentes no exterior (Colapinto, Gavinelli, Zenga \& Di Gregorio, 2015). A natureza de pequena escala das empresas significa que elas devem lidar, por um lado, com uma assimetria de poder de barganha e, por outro, com um cenário em que, muitas vezes, são obrigadas a cooperar com seus concorrentes para satisfazer a demanda internacional dos clientes (Kock, Nisuls \& Söderqvist, 2010).

Num contexto heterogêneo e intenso de interação dinâmica entre vários players, como é o caso do ambiente que cerca as PMEs de cafeicultores, a fronteira que separa as empresas é mais nebulosa, podendo perturbar a percepção do seu papel nas relações (Raza-ullah, Bengtsson \& Kock, 2014) em função do convívio nos níveis da cooperativa e da associação. Numa relação diádica estável, em que os papeis de concorrência e cooperação se mostravam evidentes, Bengtsson \& Kock (2000) descobriram, que em atividades realizadas por duas empresas em um relacionamento mais distante dos clientes finais, as empresas tendem 
a cooperar com mais frequência; já em atividades mais próximas dos compradores, como atividades de atendimento ao cliente, elas tendem a competir mais intensamente.

Mesmo no contexto cooperativo, resultante da formação das organizações, cada produtor permanece livre para acessar diferentes serviços e políticas conforme a sua disponibilidade de capital econômico e a abrangência do seu capital social (Singulano, 2015). Além disso, a sua disposição para encarar a mudança pode assumir um caráter limitador, sobretudo entre pequenos produtores, quando a aversão ao risco pode converte-se em obstáculo à adoção de novas tecnologias (Neves, Saes \& Rezende, 2003).

Esse esforço dos cafeicultores, para atender a essa nova conjuntura, exigiu flexibilidade estratégica de cada produtor, bem como das associações e suas respectivas regiões, o que abriu caminho para a inovação como meio de prepará-los para o futuro e garantir a sua sobrevivência. As restrições associadas ao tamanho dessas PMEs podem dificultar sua capacidade de inovação e crescimento, motivando-as a cooperar com seus concorrentes (Kraus et al., 2017). Administrar todas essas esferas de relacionamento exige dos cafeicultores um esforço de coordenação conjunta, que é crucial para lidar com o envolvimento do grupo nas negociações coletivas, em que o componente territorial desempenha papel importante (Correa et al., 2016; Leme et al., 2019).

\section{METODOLOGIA}

Uma vez que a coopetição e sua aplicação no setor primário ainda é relativamente inexplorada, a abordagem qualitativa exploratória parece particularmente apropriada para identificar e compreender a dinâmica que leva à criação e à promoção de relações coopetitivas visando explorar um mercado de nicho. $\mathrm{O}$ trabalho exigiu o conhecimento da história dos atores principalmente em termos de determinantes, especificidades e recursos, considerando, sempre que possível, o contexto das suas adesões à estratégia do café especial, quando estabeleceram relações de cooperação com competidores.

O trabalho classifica-se como de natureza qualitativa, pois analisa um caso partindo do entendimento das interações, significados e comportamentos humanos reais que constituem configurações organizacionais da vida real (Gephart, 2004). Para a sua realização, utilizou-se de uma pesquisa exploratória, que busca desenvolver, esclarecer e modificar conceitos e ideias (Gil, 2008), aprimorando o tema para uma investigação mais rigorosa em um estágio posterior.
Os dados qualitativos foram obtidos nas entrevistas semiestruturadas realizadas com os cafeicultores e/ou familiares, as cooperativas, as instituições apoiadoras e os gestores das associações que administram as IGs, além da análise de documentos, sítios e a observação direta do pesquisador.

Para este trabalho, foram exploradas as IGs da "Região do Cerrado Mineiro" e da "Alta Mogiana", que foram escolhidas em função do tempo de existência delas, o que permitiu observar etapas distintas da construção de relações de coopetição entre seus componentes. Assim, a primeira é a mais antiga IG de café do Brasil, um caso de sucesso e referência (Correa et al., 2016; Leme et al., 2019), de vanguarda na inovação (Valente, Emília, Moraes, Fernandes, \& Maria, 2013), formalizada em 2005 e situada no principal estado produtor de café do país, Minas Gerais; e a segunda uma IG intermediária, mais recente e em processo de amadurecimento, tendo seu processo aprovado em 2013, situando-se no estado de São Paulo. IGs mais incipientes poderiam apresentar comportamentos coopetitivos pouco proveitosos para o objeto da pesquisa.

Inicialmente, os cafeicultores das respectivas IGs foram conhecidos a partir do primeiro contato estabelecido com as associações, representadas aqui pelos seus gestores. Além da seleção dos cafeicultores entrevistados, preferencialmente engajados na exploração do comércio de café especial, esses mesmos gestores ajudaram a eleger as instituições que apoiam os cafeicultores no esforço de produção e comercialização, já que elas compõem a rede de colaboração que busca o sucesso e a solidez da reputação do café especial da respectiva região. A única demanda para a seleção dos cafeicultores feita aos gestores foi que a composição dos entrevistados fosse heterogênea, de forma a sustentar nos relatos uma gama mais variada de percepções, como cafeicultores engajados no relacionamento e coordenação da cadeia; na origem e sustentabilidade; na qualidade e diferenciação de produto, relacionadas ao Direct Trade (Guimarães, Santos, Leme \& Azevedo, 2020), bem como produtores iniciados e amadurecidos, com e sem marca própria.

A coleta foi realizada por meio de vinte entrevistas semiestruturadas, cujos detalhes podem ser observados no Quadro 1. Duas dessas entrevistas realizadas com o gestor da Alta Mogiana (entrevistas 1 e 2) e uma terceira realizada com esse mesmo gestor e mais dois cafeicultores, interagindo entre si (entrevista 3), foram importantes para validar a proposta deste trabalho. As demais entrevistas foram todas conduzidas individualmente. 
QUADRO 1 - Informações gerais a respeito das entrevistas realizadas para coleta de dados

\begin{tabular}{|c|c|c|c|c|c|c|}
\hline $\mathbf{N}^{\circ}$ & EMPRESA & REGIÃO & CARGO & DATA & TEMPO & MEIO DE CONTATO \\
\hline 1 & AMSC & Alta Mogiana & Gestor & $21 / 08 / 2018$ & $27 \mathrm{~min}$. & Skype \\
\hline 2 & AMSC & Alta Mogiana & Gestor & $13 / 09 / 2018$ & $1 \mathrm{~h} 06 \mathrm{~min}$ & Skype \\
\hline \multirow{3}{*}{3} & Cafeicultor 1 & \multirow{3}{*}{ Alta Mogiana } & Cafeicultor & \multirow{3}{*}{$11 / 10 / 2018$} & \multirow{3}{*}{$2 \mathrm{~h} 09 \mathrm{~min}$} & \multirow{3}{*}{ Presencial } \\
\hline & Cafeicultor 2 & & Cafeicultor & & & \\
\hline & AMSC & & Gestor & & & \\
\hline 4 & EMATER MG & Minas Gerais & Gestor da Agenda & $22 / 08 / 2019$ & $28 \mathrm{~min}$. & WhatsApp \\
\hline 5 & Cafeicultor 3 & Alta Mogiana & Cafeicultor & $16 / 09 / 2019$ & $41 \mathrm{~min}$. & Skype \\
\hline 6 & EPAMIG & Minas Gerais & Técnico & $23 / 09 / 2019$ & $41 \mathrm{~min}$. & WhatsApp \\
\hline 7 & Cafeicultor 4 & Alta Mogiana & Cafeicultor & $30 / 01 / 2019$ & $36 \mathrm{~min}$. & Presencial \\
\hline 8 & COCAPIL & Alta Mogiana & Gerente Comercial & $30 / 01 / 2019$ & $1 \mathrm{~h} 06 \mathrm{~min}$ & Presencial \\
\hline 9 & Cafeicultor 5 & Cerrado Mineiro & Cafeicultor & $06 / 11 / 2019$ & $41 \mathrm{~min}$. & WhatsApp \\
\hline 10 & Cafeicultor 6 & Alta Mogiana & Cafeicultor & $07 / 11 / 2019$ & $23 \min$. & WhatsApp \\
\hline 11 & Exportador Independente & Alta Mogiana & Sócio-Proprietário & $07 / 11 / 2019$ & $1 \mathrm{~h} 07 \mathrm{~min}$ & Presencial \\
\hline 12 & Cafeicultor 7 & Cerrado Mineiro & Cafeicultor & $11 / 11 / 2019$ & $1 \mathrm{~h} 42 \mathrm{~min}$ & Presencial \\
\hline 13 & $\begin{array}{c}\text { Federação dos Cafeicultores } \\
\text { do Cerrado }\end{array}$ & Cerrado Mineiro & Gestor & $11 / 11 / 2019$ & $1 \mathrm{~h} 07 \mathrm{~min}$ & Presencial \\
\hline 14 & EXPOCACCER & Cerrado Mineiro & Presidente & $11 / 11 / 2019$ & $51 \mathrm{~min}$. & Presencial \\
\hline 15 & SEBRAE MG & Cerrado Mineiro & Gestora & $12 / 11 / 2019$ & $53 \mathrm{~min}$. & Presencial \\
\hline 16 & EPAMIG & Cerrado Mineiro & Pesquisador & $09 / 12 / 2019$ & $8 \min$. & WhatsApp \\
\hline 17 & Cafeicultor 8 & Alta Mogiana & Cafeicultor & $09 / 12 / 2019$ & $24 \mathrm{~min}$. & Skype \\
\hline 18 & BSCA & Brasil & Técnico & $17 / 12 / 2019$ & $27 \mathrm{~min}$. & Telefone \\
\hline 19 & Cafeicultor 9 & Cerrado Mineiro & Cafeicultor & $18 / 12 / 2019$ & $38 \mathrm{~min}$. & WhatsApp \\
\hline 20 & Cafeicultor 10 & Cerrado Mineiro & Cafeicultor & $21 / 01 / 2020$ & $44 \mathrm{~min}$. & Telefone \\
\hline
\end{tabular}

Fonte: Elaborado pelos autores

Para fins de análise de dados, utilizou-se da técnica de análise de conteúdo. Alguns passos foram respeitados na condução da análise de conteúdo, entre os quais: i) codificação das entrevistas, a fim de reduzir o volume de material e facilitar a análise posterior; e ii) a categorização, que permitiu definir melhor as unidades de análise (Bardin, 2002), cujos detalhes podem ser observados no Quadro 2. As categorias foram elaboradas à medida que a pesquisa avançava e o volume de entrevistas com os cafeicultores e as instituições passou a exigir uma melhor coordenação das informações a fim de melhor compreendê-las e relacioná-las.

\section{RESULTADOS E DISCUSSÃO}

\subsection{Cooperação}

As entrevistas com os produtores de cafés especiais trouxeram algumas práticas adotadas por eles que evidenciam a cooperação. Os trechos das entrevistas, abaixo, agrupam práticas específicas relacionadas à comercialização dos cafés, envolvendo a indicação do produto de um concorrente durante um processo de venda, ou, contrariamente, um cafeicultor, se valendo da reputação preciosa de outro, como referência para atrair o interesse do comprador. A interação, nesse caso, dá-se dentro da esfera de cafeicultores associados da mesma Indicação Geográfica. O relacionamento parece ser construído na base da confiança, numa percepção de que a outra parte se dedica a fortalecer não apenas a sua própria posição, mas o relacionamento no mercado (Morris et al., 2007), que se traduz efetivamente no convívio estabelecido com a própria região.

O mundo do café é muito integrado, eu tenho um torrador que tem uma marca, ele divulga a gente para outros lugares, eu divulgo a marca dele para outros cafeicultores (...). A gente não tem atrito entre os cafeicultores em questão de qualidade. O Cafeicultor 2, a gente sabe que ele está com 
um café muito diferenciado, muito bom, a gente usa ele como referência para introdução em outros lugares, a gente fala o nosso café é vizinho do Cafeicultor 2, muito pontuado, a gente está seguindo o padrão deles, então assim, um atrai o outro, um engrandece o outro. (Cafeicultor 3)

Outra prática encontrada foi na divisão de custos para a montagem de um stand em feiras. A partir dos casos, foi observada contribuição das associações dos cafeicultores para participações em festivais comerciais e técnicos distintos, o que seria um custo muito alto para alguns dos produtores, torna-se factível pela organização do grupo.

O consumidor exigente de café também age nesse contexto, servindo como promotor de aproximação entre cafeicultores que, aos olhos do mercado, não passam de meros concorrentes. $\mathrm{O}$ esforço individual daqueles que visam à diferenciação amplia a oferta disponível de cafés especiais no mercado, sobretudo em negócios e empreendimentos mais amadurecidos, cuja proposta vai ao encontro dos consumidores dispostos a explorar a experiência e as nuances de cada origem específica, bem como a própria história do produtor e sua propriedade (Guimarães et al., 2019), além das variedades raras e dos microlotes. Incapazes de saciar todas as necessidades desse consumidor exigente, que valoriza a alternativa de escolha e o cuidado com a seleção sem se prender a marcas (Silva, Gusmão, Barros, Azevedo \& Junior, 2015; Guimarães et al., 2019), resta aos interessados em explorar esse nicho de mercado, pedir ajuda aos seus concorrentes. A passagem abaixo explora este aspecto:

Acontece sempre, por exemplo, eu vendo para as cafeterias o meu café, ele tem uma característica própria, da região, e do nosso café, ele é um café encorpado, doce, acidez baixa, e um corpo elevado, essa é a característica do meu café. Aí eu chego na cafeteria e ele quer um café orgânico da nossa região (ou) um café que tenha uma acidez mais alta, eu indico rapidamente um que eu sei que naquele ano está com a acidez legal. (...) então a gente está sempre fazendo isso, eu indicando alguém, ou alguém me indicando, isso faz parte desse mundo do café especial. (Cafeicultor 3)

A relação entre os cafeicultores também se mostrou importante para permitir o acesso de integrantes menos favorecidos da associação a mercados internacionais de grande distância psíquica. Um dos membros associados da Alta Mogiana estabeleceu relacionamento com compradores de cafés especiais japoneses. Posteriormente, diante da elevada demanda exigida pelo comprador, convidou para negociar diretamente com essa fonte alguns outros associados, cujo padrão de produção ele julgava confiável. Conforme citação do próprio produtor que estabeleceu a relação:

Eu fui convidado pelo Itamarati para estar lá, exercer esse papel de café do Brasil nessa feira do Japão, com isso eu pensei... vou levar a região junto e outros produtores, daí eu abri para outros produtores, quem veio foi junto, e teve gente que não quis. (Cafeicultor 2) favorecido:

Intercalada pela intervenção de um produtor

Na verdade, foi um grupo selecionado, quem a gente sabe que tem qualidade, já faz um trabalho em cima de rastreabilidade e certificação, de 11 só uns 4 conseguiram. (Cafeicultor 1)

QUADRO 2 - Categorias e subcategorias para a análise de dados

\begin{tabular}{|c|c|c|c|}
\hline $\begin{array}{l}\text { DADOS A SEREM } \\
\text { COLETADOS }\end{array}$ & CATEGORIAS & SUBCATEGORIAS & $\begin{array}{l}\text { REFERENCIAL } \\
\text { TEÓRICO }\end{array}$ \\
\hline \multirow{2}{*}{$\begin{array}{l}\text { Relação entre os cafeicultores, } \\
\text { relação entre as cooperativas e } \\
\text { relação entre as associações }\end{array}$} & Competição & $\begin{array}{l}\text { Competição por mercados, } \\
\text { produtos, serviços, tempo, } \\
\text { atenção e recursos }\end{array}$ & \multirow{2}{*}{$\begin{array}{l}\text { Bengtsson e Kock (2000); } \\
\text { Porter (1990); Raza-ullah et } \\
\text { al. (2014); Kraus et al. (2017); } \\
\text { Morris et al. (2007); Czakon \& } \\
\text { Rogalski (2014) }\end{array}$} \\
\hline & Cooperação & $\begin{array}{c}\text { Ações, motivações, } \\
\text { benefícios, dificuldades, } \\
\text { assimetrias }\end{array}$ & \\
\hline Inovação na cafeicultura & $\begin{array}{l}\text { Atividades Inovadoras em } \\
\text { Produto e Processo } \\
\text { (marketing, treinamento de } \\
\text { pessoal, desenvolvimento } \\
\text { de software e Propriedade } \\
\text { Intelectual) }\end{array}$ & $\begin{array}{c}\text { Rastreabilidade e } \\
\text { Emprego de Tecnologia } \\
\text { (lavoura, armazenamento } \\
\text { e comércio) }\end{array}$ & $\begin{array}{l}\text { Neves et al. (2003); Daviron } \\
\text { e Ponte (2005); Guimarães } \\
\text { et al. (2019); Guimarâes et } \\
\text { al. (2020); Mascarenhas e } \\
\text { Wilkinson (2014) }\end{array}$ \\
\hline
\end{tabular}

Fonte: Elaborado pelos autores

Organizações Rurais \& Agroindustriais, Lavras, v. 22, e1699, 2020 
Finalizada pelo produtor que estabeleceu a relação:

Eu estou tentando sempre abrir, eu não consigo vender café para o mundo inteiro e eu nem quero virar uma corretora de café, eu quero que o pessoal faça que nem eu faço, venda direta com menos atravessadores e ganhar uns zeros a mais da cadeia. (Cafeicultor 2)

Alinhado com os resultados da pesquisa, conduzida por (Colapinto et al., 2015), pertencer a uma rede possibilitou aos produtores superarem algumas das dificuldades encontradas no processo de internacionalização, como por exemplo, a dificuldade relacionada ao porte do produtor. Produtores que sozinhos não supririam as demandas de um determinado mercado externo, por pertencerem a uma associação de empresas similares, podem estabelecer parcerias com outros associados para suprir a demanda requerida, conforme descobertas da pesquisa de Kock et al. (2010). Essa relação horizontal também acontece com outros atores da cadeia de café. O trecho a seguir foi extraído da entrevista com um exportador, que convive com essa relação, e esclarece a postura "conflitante" de concorrente e competidor que cerca os relacionamentos estabelecidos nessa esfera, regidos pela lógica da expressão "uma mão lava a outra."

Eu que estou só na ponta da comercialização preciso de parceiros, que são meus concorrentes, eles também exportam, mas eu preciso deles, muitas vezes para identificar um lote, ou para rebeneficiar esse lote, ou para armazenar esse lote. (PERGUNTA: De que forma eles são seus concorrentes?) Eles fazem o mesmo trabalho, eles também exportam. Um armazém, uma pequena cooperativa, ele é meu concorrente. Até um produtor que faz uma venda direta acaba sendo um concorrente. (Exportador Independente Alta Mogiana)

A cooperação também se manifesta quando o assunto é a certificação das propriedades. Alguns mercados específicos, especialmente internacionais, exigem dos cafeicultores determinadas práticas associadas aos selos que elas transmitem aos seus consumidores. A sustentabilidade, por exemplo, é um assunto sensível que gera desconfiança no consumidor final, e, por consequência, demanda um tipo de comprovação emitida por quem tenha alguma credibilidade ou autoridade legal, no caso, as certificadoras. A conformação aos critérios estabelecidos pelas certificadoras eleva os custos de produção, o que pode excluir os pequenos produtores desses mercados (Silva et al., 2015). A fim de evitar a sua exclusão desses mercados, os pequenos e médios produtores unem forças para poderem participar desse "jogo".
Que hoje o Cerrado Mineiro tem 110.000 hectares de área de café com algum tipo de certificação de boas práticas. Isso acabou que foi muito bom, (...) e a gente tinha recurso do SEBRAE pra poder atuar formando grupos de produtores; e pagando a parte de auditorias desses grupos, uma das partes mais caras do processo de certificação (...) quando você forma o grupo você dilui isso, e fica mais em conta, mais viável para o produtor poder entrar no grupo e poder certificar todo o grupo e auditar por sorteio, por amostragem. (Gestor da Federação dos Cafeicultores do Cerrado)

Por representarem um elo de comunicação formal estabelecido entre o processo produtivo e o mercado consumidor, as certificações demandam por parte dos cafeicultores um planejamento adequado, a adoção de uma estratégia bem definida que norteará a relação custo/ disposição/tempo em função do valor gerado pelo selo, na expectativa de que seja sempre vantajosa.

Esse senso de coletividade adotado para o processo de certificação também foi abordado por um cafeicultor do Cerrado Mineiro. Uma questão interessante envolvida no relato diz respeito ao comprometimento dos membros constituintes com o rigor das demandas associadas à certificação, já que uma inconsistência individual pode resultar em uma penalidade para o grupo inteiro.

Eu estou numa região que não tem grandes cafeicultores, mas tem muita informação, (...) a gente reuniu dez pessoas e a gente faz parte do grupo da RAINFOREST. Então a gente sempre troca ideia, todo mês a gente senta, conversa, principalmente questão de leis trabalhistas, ambientais, a gente divide consultor (...) a gente tem uma pessoa paga por nós que vai nas fazendas para fazer auditoria, pra colocar todo mundo no mesmo nível. Porque senão um cara que está no grupo, ele me derruba. Se ele não estiver no mesmo nível. Se ele chega lá e tiver um trabalhador que não está fichado e pegar, ai o grupo inteiro é exonerado. Todo mundo, e dá o maior problema. É como se nós nos fiscalizássemos. (Cafeicultor 9)

A cooperação extrapola a esfera da relação estabelecida entre os cafeicultores, e suas propriedades (seus negócios), e também encontra espaço para se manifestar na relação entre as cooperativas. As cooperativas mantêm uma relação comercial entre si, que aflora em circunstâncias específicas, por exemplo, quando um negócio fechado por uma das partes exige um complemento de produto da outra parte para honrar um acordo firmado. A relação, nesse caso, é mediada pela transação financeira, em forma de compra-revenda ou comissionamento. Essa prática condiz com a abordagem ganha-ganha explorada por Della Corte \& Aria (2016), em que empresas que 
desfrutam de melhor desempenho também podem produzir benefícios econômicos para outros atores envolvidos nas mesmas atividades e vice-versa. Como as cooperativas são constituídas pelos próprios cafeicultores, que além de donos mantêm uma relação vertical direta com elas, de compra (de insumos) e venda (de grãos), a propensão delas em cooperar é positivamente afetada. Esse aumento dos relacionamentos comerciais é um dos desdobramentos possíveis (Della Corte \& Aria, 2016).

A cooperativa $X$ hoje, tanto os outros armazéns, a gente é lógico que tem a concorrência, eles são fornecedores também nosso, a gente compra café deles. Esse ano a gente comprou quase 9.000 sacas de café da cooperativa $X$. (Gerente Comercial COCAPIL)

Por fim, a última evidência de cooperação encontrada foi na troca de material entre cafeicultores, especificamente maquinário e implementos, necessários para a colheita do fruto. O relato foi dado apenas pelo menor produtor entrevistado, no que diz respeito à área de plantio, o que pode ser uma prática mais afeita, embora não exclusiva, aos cafeicultores mais carentes de recursos.

(FILHO) Entre o pessoal aqui da região, temos interação, troca de serviço, maquinário. Às vezes eu não tenho um maquinário que eu preciso, eu pego emprestado com o vizinho. (MÃE) Eu e meu marido nós trocávamos serviço com o vizinho, na época de colheita ele vinha e ajudava a gente e depois o meu marido ia e ajudava ele. (...) E o custo, sai um custo menor. (Cafeicultor 7)

\subsection{Competição}

As entrevistas com os cafeicultores trouxeram algumas práticas adotadas que evidenciam a concorrência entre eles. Uma forma de manifestação do espírito competitivo se dá pela ascensão do orgulho, do amor-próprio, da vaidade, do ego exacerbado que atinge o cafeicultor quando a qualidade do seu produto é reconhecida, podendo despertar uma avidez latente que se converte em estímulo para alcançar o patamar de reconhecimento alheio. Isso ilustra o "direito de se gabar" (tradução livre de "bragging rights"), decorrente da relação de rivalidade estabelecida por concorrentes geograficamente próximos, ou seja, que "os rivais domésticos se envolvem em feudos ativos; eles competem não apenas por participação de mercado, mas também por pessoas, por excelência técnica e talvez o mais importante, pelo direito de se gabar" (Porter, 1990, p. 85).

O que eu vejo, dos produtores que estão em um patamar inferior, mas que conhecem esse outro mundo, esses produtores passam a ser referência. Ele vira modelo. (...) Quando sai na mídia, a venda de um café a um preço elevado eu acho que passa a ser um estímulo para os outros, pelo menos melhorar um pouco, pode ser que às vezes assim mexe com um pouco do ego, a gente escuta muito, por exemplo, assim né "sei quem vendeu café, aí o outro fala, mas é um lotezinho, um microlote de 10 sacas". Parece que às vezes rola um despeito, vamos dizer assim, eu penso que viram modelos, produtores modelos que outros querem copiar né. Não vejo uma competição. (Técnico EPAMIG)

Ainda que alguns entrevistados amenizem o discurso, chegando a desconsiderar o ímpeto competitivo decorrente dessa convivência íntima, outro exemplo mais evidente, envolvendo a exposição financeira dos ganhos obtidos pela adoção das práticas associadas ao café especial, deixam transparecer melhor essa qualidade ou característica.

Essa competição é muito saudável, tanto para o produtor quanto para o mercado. Por que isso acontece? (...) alguns produtores começaram a certificar e a melhorar a qualidade dos seus cafés, começaram a ser campeões em concursos, a vender cafés com o preço diferenciado, e a ganhar dinheiro mesmo com isso. (...) alguns tem inclusive pequenas cafeterias dentro da fazenda e o vizinho continuava com aquelas práticas arcaicas. E começa a haver uma pessoa na mesma condição dele mudando de vida, e isso cria uma provocação grande. Então ele começa, a ele mesmo se sentir provocado, ele vê os filhos daquele vizinho se tornando atores desse processo, e ele quer que o filho também se torne ator. (Gestor EMATER MG)

Uma das esferas em que a competição se manifesta é na demanda de serviço gerada pelos cafeicultores às cooperativas. A grande maioria dos cafeicultores não tem maquinário para processar o café no pós-colheita, realizar o seu beneficiamento e armazenar o produto adequadamente. Os produtores costumam fazer o serviço de secagem do grão em terreiro próprio e logo o despacham para as cooperativas, que abrigam a maior parte dos cafés das regiões. A Região do Cerrado Mineiro conta com 7 cooperativas e 5 armazéns credenciados que disputam entre si a preferência dos cafeicultores, sem contar os outros empreendimentos existentes que não compõem o ambiente da Federação. Ainda que parte desse complexo se encontre distribuído em 9 cidades, e a proximidade com a propriedade seja fator determinante para a escolha do produtor, a oferta de serviços é grande, resultando em um ambiente de alta concorrência entre as próprias associações.

Se manifesta quase que em toda a linha, vamos falar assim, em termos de demanda de serviço, não é só no especial. O cara fez uma venda, mesmo de um café baixo, ele quer preparar, e se ele não entregar ele não recebe. A

Organizações Rurais \& Agroindustriais, Lavras, v. 22, e1699, 2020 
demanda é constante, e ela é exigente. A gente tem que ter uma atenção importante nisso, para que você tenha uma fidelização do cliente ao seu serviço, do nosso cooperado ao seu serviço, porque máquina de preparo tem, (...) se a gente não fizer um bom serviço nego vai para o outro. Então, existe uma exigência do cliente cooperado. (...) Mas eu acho assim, a questão de contratar serviço, demandar armazenagem, (...) faz parte do nosso negócio: (...) primeiro ponto que se vende é confiança e o segundo é a sua presteza de serviço (...). (Presidente EXPOCACCER)

Especialmente para os novos produtores de cafés especiais, a velocidade da informação e conhecimento entrantes é mais acelerada do que a absorção da competência necessária para poder processá-los. A fim de equalizar esse trâmite, que tende a suavizar com a passagem do tempo, é comum dispor do auxilio de um profissional para acelerar o processo de aprendizado e evitar o desperdício do tempo transcorrido. A busca permanente por essa alternativa pressiona o mercado de profissionais habilitados a exercer essa função, cujo desdobramento natural é o aumento da concorrência entre os cafeicultores. A competição, nesse caso, é por recursos e/ou atenção. A passagem abaixo traz à tona essa questão:

A associação é para a gente ir para algumas feiras. Porque a associação não traz clientes, não indica, não faz vendas, nada disso. A associação não ajuda com orientação de como a gente faz uma secagem, a gente teria que buscar pessoas especialistas ali, técnicas, por exemplo, tem o agrônomo lá que já trabalha pra nós, que é da cooperativa $X$, e ele é muito bom, (...). E ele ainda ganha comissões em cima das compras que a gente faz lá. Ele que indica. Ele passa a receita, a gente compra lá. E ele ainda ganha comissão, também. Só que, além disso, nós estamos estudando uma possibilidade de pagar uma mensalidade para ele, pra ver se ele dá uma atenção maior para a gente. Difícil isso né? Ele é funcionário da cooperativa $X$, nós somos associados, ele ganha um bom salário, só que mesmo assim estão me falando isso. (Cafeicultor 4)

As cooperativas, responsáveis por processar a maior parte do café disponível no mercado, para onde converge boa parte dos serviços de pós-colheita, são impactadas com essa carga adicional de trabalho proveniente das particularidades atreladas ao processamento de cafés especiais (armazenamento, beneficiamento, rebeneficiamento, etc.). Essa nova demanda de atividades, altera a natureza do serviço prestado, que passa a ser incorporada à rotina dos profissionais envolvidos, nem sempre preparados para absorvê-las. Nesse contexto, a atenção dispensada aos cafeicultores acaba comprometida, gerando cobrança para que ela seja restaurada. Os serviços prestados seguem a mesma lógica, e o relato a seguir complementa o anterior:
Dá muito trabalho. Eu falo que a partir do momento que a gente começou a vender cafés especiais, meu trabalho mudou bastante. (...) e a questão da exportação ainda mais, gringo é toda a semana, visita, lógico que eles querem te conhecer, eles querem conhecer a sua estrutura, como você trabalha, como você trata aquela mercadoria, (...). Toma muito tempo essa parte da exportação. Em época de safra a gente chega a provar 4 ou 5 mesas por dia, cabem 28 amostra em cada mesa. É de 120 a 150 amostras por dia. As últimas mesas normalmente você tem que repetir ela no próximo dia, porque você está cansado demais, seu paladar já está..., você não está pegando mais nada. (...). (Gerente Comercial COCAPIL)

Por último, as associações que administram as Indicações Geográficas, e seus respectivos membros, estão sempre buscando verbas e/ou patrocínios para promoverem as suas regiões e os diferenciais associados a elas. Naturalmente, o volume de cafeicultores interessados em usufruir dessas oportunidades de exposição costuma ser maior do que a disponibilidade limitada de espaço que eles gozam para serem atendidos em igualdade de condições. Dessa forma, as associações e seus membros competem por acesso a recursos e oportunidades de exposição. A parceria da BSCA com a APEX envolve o acesso a verbas para a participação em feiras, eventos, missões, congressos, etc.

O que a gente faz para os nossos membros é abrir espaço em feiras, essas coisas são até bem recorrentes, mesa de cupping, rodada de negócios. Então são oportunidades que a gente abre nas feiras que a gente realiza. Ai, essa questão é até uma demanda muito recorrente, de a gente não conseguir agregar todo mundo, porque realmente o Brasil é um país muito extenso (...). (Técnico da BSCA)

Contrariando os resultados do estudo de Bengtsson e Kock (2000), em que a competição se manifestou nas atividades mais próximas ao consumidor e a cooperação nas atividades mais distantes do consumidor, as práticas que vieram à tona, nas entrevistas conduzidas para esta pesquisa, parecem se manifestar em sentido contrário. Deve ser levado em conta que os casos explorados pela pesquisa de Bengtsson \& Kock (2000) envolviam representantes da indústria de revestimento (Suíça), da indústria cervejeira (Suíça) e da indústria de laticínios (Finlândia): segmentos da atividade secundária em países desenvolvidos. Esses achados reforçam a percepção compartilhada pelos próprios cafeicultores de que o envolvimento deles com a comercialização sempre foi muito baixo, ou quase inexistente, embora, aos poucos, eles comecem a se assenhorear dela, ainda que muito dependentes da via coletiva. 
Os perfis dos segmentos explorados também divergem: enquanto os segmentos industriais dos casos explorados pela pesquisa de Bengtsson \& Kock (2000) são constituídos por poucos produtores e muitos consumidores, no caso desta pesquisa com cafés especiais, são muitos produtores para poucos transformadores/intermediários (indústria de torrefação, empresas de varejo, exportadoras, importadoras, etc.). Na primeira, a indústria é vendedora (vende produto manufaturado); na segunda, a indústria é compradora (compra produto para manufaturar).

Além disso, os cafeicultores se encontram em um formato de agremiação diferenciado, que visa criar uma identidade forte, um brand equity coletivo (a própria Indicação Geográfica), ao contrário das indústrias exploradas por Bengtsson \& Kock (2000), cuja cooperação apresentava um caráter mais oculto, menos expositivo, ainda que elas fossem representadas por associações. De qualquer forma, o que parece determinar as atividades em que prevalecem a cooperação ou a competição são as particularidades do segmento analisado, não exatamente a proximidade ou a distância da atividade explorada em relação ao consumidor.

O Quadro 3 traz o resumo dos resultados encontrados na pesquisa para a coopetição em níveis distintos.

QUADRO 3 - Apresentação de Resultados

\begin{tabular}{|c|c|c|}
\hline $\begin{array}{l}\text { Nível de } \\
\text { Interação }\end{array}$ & $\begin{array}{l}\text { Estratégia } \\
\text { Interativa }\end{array}$ & Resultados Encontrados \\
\hline \multirow[b]{4}{*}{ Cafei } & \multirow{6}{*}{ Cooperação } & $\begin{array}{c}\text { COMERCIAL: apoio mútuo para atender demanda de volume e qualidade de } \\
\text { importador }\end{array}$ \\
\hline & & $\begin{array}{l}\text { COMERCIAL: apoio mútuo para atender a demanda do consumidor mais exigente, } \\
\text { interessado em alternativas }\end{array}$ \\
\hline & & COMERCIAL: divisão de stand em feira \\
\hline & & COMERCIAL: troca de contato de fornecedores \\
\hline \multirow{5}{*}{$\begin{array}{l}\text { Cafeicultor } \\
\text { Interpessoal } \\
\text { e Inter- } \\
\text { organizacional }\end{array}$} & & PROCESSO e COMERCIAL: certificação sustentabilidade \\
\hline & & $\begin{array}{c}\text { RECURSOS MATERIAIS e SERVIÇOS: troca de material entre cafeicultores e troca } \\
\text { de serviços }\end{array}$ \\
\hline & \multirow{3}{*}{ Competição } & $\begin{array}{l}\text { PRODUTO e PROCESSO: Ego exacerbado quando a qualidade do seu produto é } \\
\text { reconhecida, podendo se converter em inveja por parte de alguns dos seus pares, ou em } \\
\text { estímulo para alcançar o patamar de reconhecimento alheio }\end{array}$ \\
\hline & & $\begin{array}{l}\text { SERVIÇO: aumento da demanda por profissionais específicos com conhecimento em } \\
\text { cafés especiais }\end{array}$ \\
\hline & & $\begin{array}{l}\text { ATENÇÃO: aumento da demanda de serviço atrelado às práticas do café especial } \\
\text { gera uma concorrência dos cafeicultores por atenção dos gestores e/ou lideranças }\end{array}$ \\
\hline \multirow{2}{*}{$\begin{array}{l}\text { Cooperativa } \\
\text { Cooperativa } \\
\text { Inter- } \\
\text { organizacional } \\
\text { e Inter-redes }\end{array}$} & Cooperação & $\begin{array}{l}\text { COMERCIAL: As cooperativas mantêm uma relação comercial entre si, que aflora } \\
\text { em circunstâncias específicas, entre as quais um negócio fechado por uma das partes } \\
\text { que exige um complemento de produto da outra parte para honrar o acordo firmado }\end{array}$ \\
\hline & Competição & $\begin{array}{c}\text { SERVIÇO: A demanda por serviço é constante e exigente. As cooperativas têm que } \\
\text { se atentar para isso, em busca da fidelização do cliente (o cafeicultor) ao seu serviço. } \\
\text { A oferta de serviços é grande, sobretudo na Região do Cerrado Mineiro, promovendo } \\
\text { um ambiente de competição acirrada }\end{array}$ \\
\hline \multirow{2}{*}{$\begin{array}{l}\text { Associação } \\
\text { Associação } \\
\text { Inter-redes }\end{array}$} & Cooperação & $\begin{array}{l}\text { JURÍDICO-COMERCIAL: colaboração jurídica entre as associações gestoras das } \\
\text { Indicações Geográficas para acionar criminalmente empresas que fazem uso indevido } \\
\text { das marcas regionais registradas no INPI }\end{array}$ \\
\hline & Competição & $\begin{array}{l}\text { RECURSOS FINANCEIROS: As associações gestoras das Indicações Geográficas } \\
\text { competem entre si por recursos financeiros destinados pela APEX à BSCA para a } \\
\text { promoção de eventos, feiras, congressos, missões e etc. }\end{array}$ \\
\hline
\end{tabular}

Fonte: Elaborada pelos autores

Organizações Rurais \& Agroindustriais, Lavras, v. 22, e1699, 2020 


\section{CONSIDERAÇÕES FINAIS}

A fim de analisar como a coopetição se manifesta entre os produtores de cafés especiais em decorrência da busca pela qualidade superior do grão, o presente estudo apresentou um panorama dos relacionamentos na cafeicultura brasileira, no nível das PMEs e das instituições que as apoiam, identificando os comportamentos competitivos e cooperativos entre os atores envolvidos. Os esforços de pesquisa foram direcionados para a exploração dos relacionamentos no âmbito da produção, envolvendo a prestação de serviço e a qualidade material do produto, e no âmbito comercial, envolvendo a promoção, comercialização e a imagem do café especial.

A pesquisa explorou a coopetição em diferentes níveis ao investigar a interação cafeicultor-cafeicultor, cooperativa-cooperativa, associação-associação dentro do contexto de duas IGs, com novos relacionamentos se formando e antigos relacionamentos se reconfigurando, a fim de atender às exigências do mercado de cafés especiais. A necessidade de cooperação se mostrou onipresente no âmbito comercial, e a competição se manifestou em produtos, processos, serviços e finanças. Essa abordagem da coopetição em diferentes níveis de interação é pouco investigada, tendo constituído o alerta para futuras contribuições no trabalho de Bengtsson \& Raza-Ullah (2016).

O discurso ressonante aflorado pela emergência do café especial é o da venda direta (Direct Trade), que materializa o esforço efetivo de aproximação entre as partes produtoras e consumidoras. A cooperação nos múltiplos níveis das IGs de cafés reforça a intenção de descomoditizar o produto, cuja vulnerabilidade comercial sempre foi desafiadora para os cafeicultores. Essa fragilidade necessita ser enfrentada "em bloco" para atingir os efeitos esperados: melhorar o nível de controle da comercialização do café, físico e narrativo, bem como reduzir as assimetrias de poder na cadeia de abastecimento (Guimarães et al., 2020). Já a competição nos múltiplos níveis das IGs de cafés abrange o produto propriamente dito, e os processos e serviços diferenciados atrelados à sua consecução. Essa competição pressiona os limites estruturais das IGs, cujo dimensionamento impreciso tende a impactar mais o pequeno produtor, carente de recursos, do que o grande. Para cafeicultores e gestores de cooperativas e associações é importante reconhecer a existência da competição, a fim de minimizar os conflitos provenientes dessa "nova" relação.
A ascensão do café especial representa uma ruptura em relação aos meios de produção e comercialização do café commodity, "exigindo novas competências nas empresas, novos perfis de recursos humanos, novas sugestões sobre se, quando e como partilhar conhecimentos com os outros" (Della Corte, 2018, pg. 10). Mesmo em um segmento regido essencialmente pela lógica do mercado de commodities, cujo vocabulário dominante é composto por termos como estabilidade, aprimoramento, produção e eficiência, existe espaço para a variação, assunção de riscos, experimentação e inovação (March, 1991).

A produção de cafés especiais não elimina, necessariamente, a produção do café commodity, pois este continuará sendo produzido, mesmo em propriedades onde seja intensificada a produção de cafés de qualidade superior. Sendo assim, as duas mentalidades devem permanecer convivendo dentro do indivíduo, da empresa, da associação, da cooperativa, desde o nível intraorganizacional até o nível inter-redes. Cooperação e competição estratégicas coexistindo em todos os níveis (Strese, Meuer, Flatten \& Brettel, 2016).

Além da própria metodologia adotada, que pode ser considerada uma limitação do trabalho, uma vez que se trata de uma pesquisa qualitativa exploratória, a análise está sujeita a interpretação dos pesquisadores, cuja experiência com a literatura de inovação deve ser reconhecida como fator de influência. Naturalmente, as especificidades das regiões e do período explorados podem dificultar a sua generalização para outros segmentos e Indicações Geográficas, que dependem particularmente das estruturas de governança e coordenação desenvolvidas (Leme et al., 2019).

Por fim, este trabalho não explorou a coopetição entre os níveis da IG, como cafeicultor-cooperativa, cafeicultor-associação e cooperativa-associação. O melhor entendimento dessas interações, dos seus limites e de suas possibilidades pode ser um instrumento valioso para a estruturação de novas IGs, bem como para o melhor aproveitamento das já existentes, constituindo, portanto, um foco para futuros estudos.

\section{AGRADECIMENTOS}

Agradecemos aos profissionais vinculados às organizações pesquisadas, que, em entrevistas e por meio de documentos, nos concederam as informações fundamentais para que este trabalho fosse realizado. 


\section{REFERÊNCIAS}

BARDIN, L. (2002). Análise de conteúdo. Edições 70.

BENGTSSON, M., \& KOCK, S. (2000). "Coopetition" in business networks - To cooperate and compete simultaneously. Industrial Marketing Management, 29(5), 411-426. https://doi.org/10.1016/S00198501(99)00067-X

BENGTSSON, M., \& KOCK, S. (2014). CoopetitionQuo vadis? Past accomplishments and future challenges. Industrial Marketing Management, 43(2), 180-188. https://doi.org/10.1016/j.indmarman.2014.02.015

BENGTSSON, M., \& RAZA-ULLAH, T. (2016). A systematic review of research on coopetition: Toward a multilevel understanding. Industrial Marketing Management, 57, 23-39. https://doi.org/10.1016/j. indmarman.2016.05.003

BOUNCKEN, R. B., GAST, J., KRAUS, S., \& BOGERS, M. (2015). Coopetition: a systematic review, synthesis, and future research directions. Review of Managerial Science, 9(3), 577-601. https://doi.org/10.1007/s11846015-0168-6.

BOWEN, S. (2010). Development from Within? The Potential for Geographical Indications in the Global South. The Journal of World Intellectual Property, 13(2), 231-252. https://doi.org/10.1111/j.17471796.2009.00361.x.

COLAPINTO, C., GAVINELli, L., ZENGA, M., \& DI GREGORIO, A. (2015). Different approaches to the pursuit of internationalization by Italian SMEs. Journal of Research in Marketing and Entrepreneurship, 17(2), 229-248. https://doi.org/10.1108/JRME-11-20140030 .

CORREA, C., FANTE, D. L., \& DALlABRIDA, V. R. (2016). Governança territorial em experiências de indicação geográfica : análises e prospecções [1]. Desernvolvimento Regional Em Debate, 6, 228-246.

CZAKON, W., \& ROGALSKI, M. (2014). Coopetition literature landscape - a systematic literature review 1997 - 2010. Journal of Economics \& Management, 17, 121-150.
DAVIRON, B., \& PONTE, S. (2005). The Coffee Paradox - Global Markets, Commodity Trade, and the Elusive Promise of Development (2013th ed.). ZED BOOKS.

DELLACORTE, V. (2018). Innovation through coopetition: Future directions and new challenges. Journal of Open Innovation: Technology, Market, and Complexity, 4(4). https://doi.org/10.3390/joitmc4040047.

DELLA CORTE, V., \& ARIA, M. (2016). Coopetition and sustainable competitive advantage. The case of tourist destinations. Tourism Management, 54, 524-540. https:// doi.org/10.1016/j.tourman.2015.12.009.

DEVECE, C., RIBEIRO-SORIANO, D. E., \& PALACIOSMARQUÉS, D. (2019). Coopetition as the new trend in inter-firm alliances: literature review and research patterns. Review of Managerial Science, 13(2), 207-226. https:// doi.org/10.1007/s11846-017-0245-0.

ENGEL, J. S., \& DEL-PALACIO, I. (2011). Global clusters of innovation: The case of Israel and Silicon Valley. California Management Review, 53(2), 27-49. https://doi.org/10.1525/cmr.2011.53.2.27

GEPHART, R. P. (2004). Qualitative Research and the Academy of Management Journal. Academy of Management Journal, 47(4), 454-462. https://doi.org/1 $0.1080 / 19369816.2018 .1541945$.

GIL, A. C. (2008). Métodos e Téenicas de Pesquisa Social. ( 6 ed.). Editora Atlas.

GNYAWALI, D. R., \& PARK, B. R. (2009). Co-opetition and Technological Innovation in Small and Medium-Sized Enterprises: A Multilevel Conceptual Model. Journal of Small Business Management, 47(3), 308-330. https:// doi.org/10.1111/j.1540-627X.2009.00273.x.

GUIMARÃES, E. R., LEME, P. H. M. V., DE REZENDE, D. C., PEREIRA, S. P., \& DOS SANTOS, A. C. (2019). The brand new Brazilian specialty coffee market. Journal of Food Products Marketing, 25(1), 49-71. https://doi. org/10.1080/10454446.2018.1478757.

GUIMARÃES, E. R., SANTOS, A. C., LEME, P. H. M. V., \&AZEVEDO, A. DA S. (2020). Direct Trade in the Specialty Coffee market: contributions, limitations and new lines of resear. Review of International Business, 15(3), 01-17. 
INPI. (2021). Panorama da IGs brasileiras Registradas. Retrieved June 7, 2021, from https:/www.gov.br/inpi/ pt-br/servicos/indicacoes-geograficas/explorador-deindicacoes-geograficas.

KOCK, S., NISULS, J., \& SÖDERQVIST, A. (2010). Co-opetition: A source of international opportunities in Finnish SMEs. Competitiveness Review, 20(2), 111-125. https://doi.org/10.1108/10595421011029839.

KRAUS, S., SCHMID, J., \& GAST, J. (2017). Innovation through coopetition: An analysis of small-and mediumsized trust companies operating in the liechtenstein financial centre. International Journal of Business Science and Applied Management, 12(1), 44-60.

LEME, P. H. M. V., AGUIAR, B. H., \& DE REZENDE, D. C. (2019). A convergência estratégica em Arranjos Produtivos Locais: Uma análise sobre a cooperação entre atores em rede em duas regiões cafeeiras. Revista de Economia e Sociologia Rural, 57(1), 146-159. https:// doi.org/10.1590/1234-56781806-94790570109.

LEVY, M., LOEBBECKE, C., \& POWELL, P. (2003). SMEs, CO-OPETITION AND KNOWLEDGE SHARING : THE IS ROLE. European Journal of Information Systems, 12(1), 3-17. https://doi. org/10.1057/palgrave.ejis.3000439.

MARCH, J. G. (1991). Exploration and exploitation in organizational learning. Organization Science, 2(1), 71-87.

MASCARENHAS, G., \& WILKINSON, J. (2014). Indicações geográficas em países em desenvolvimento: potencialidades e desafios. Revista de Política Agrícola, 23(2), 103-115.

MIONE, A. (2009). When entrepreneurship requires coopetition: the need for standards in the creation of a market. International Journal of Entrepreneurship and Small Business, 8(1), 92. https://doi.org/10.1504/ IJESB.2009.024107.

MORRIS, M. H., KOCAK, A., \& ÖZER, A. (2007). Coopetition as a small business strategy: implications for performance. Journal of Small Business Strategy, $18(1), 35-55$.
NEVES, M. F., SAES, M. S. M., \& REZENDE, C. L. (2003). Estudo de Caso: Illycafé e os desafios do crescimento no Brasil. In S. R. GIORDANO \& C. L. REZENDE (Eds.), Cadernos da universidade illy do café Vol. 1 (pp. 61-121). São Paulo: PENSA FIA FEA USP.

NIEDERLE, P. A., MASCARENHAS, G. C. C., \& WILKINSON, J. (2017). Governança e Institucionalização das Indicações Geográficas no Brasil. Revista de Economia e Sociologia Rural, 55(1), 85-102. https://doi. org/10.1590/1234-56781806-94790550105.

PORTER, M. E. (1990). The Competitive Advantage of Nations. Harvard Business Review, 17(1), 71-91. https:// doi.org/10.1177/014920639101700113.

QUEIROZ, T. R. (2015). Rede entre organizações nos agronegócios. In Agronegócios: Gestão, Inovação e Sustentabilidade (1 ${ }^{\text {a }}$,pp. 79-101). São Paulo: Saraiva.

RAZA-ULLAH, T., BENGTSSON, M., \& KOCK, S. (2014). The coopetition paradox and tension in coopetition at multiple levels. Industrial Marketing Management, 43(2), 189-198. https://doi.org/10.1016/j. indmarman.2013.11.001.

RENNA, P., \& ARGONETO, P. (2012). Capacity investment decision in co-opetitive network by information sharing. Computers and Industrial Engineering, 62(1), 359-367. https://doi.org/10.1016/j. cie.2011.10.011.

SAES, M. S. M., JAYO, M., \& DA SILVEIRA, R. L. F. (1997). Caccer: coordenando ações para a valorização do Café do Cerrado. São Paulo: VII Seminário Internacional PENSA de Agribusiness.

SILVA, E. C., GUSMÃO, A. K. H., BARROS, M. DE, AZEVEDO, A. DA S., \& JUNIOR, L. G. DE C. (2015). Governança privada e sustentabilidade na indústria do café. In XVII ENGEMA - Encontro Internacional sobre Gestão Empresarial e Meio Ambiente (p. 17).

SINGULANO, M. A. (2015). Desregulamentação e mudança institucional no mercado de café. In XVII Congresso Brasileiro de Sociologia (pp. 1-20). Porto Alegre. 
STRESE, S., MEUER, M. W., FLATTEN, T. C., \& BRETTEL, M. (2016). Examining cross-functional coopetition as a driver of organizational ambidexterity. Industrial Marketing Management, 57, 40-52. https:// doi.org/10.1016/j.indmarman.2016.05.008
VALENTE, R., EMÍLIA, M., MORAES, R. DE, FERNANDES, V., \& MARIA, S. (2013). O processo de reconhecimento das indicações geográficas de alimentos e bebidas brasileiras : regulamento de uso, delimitação da área e diferenciação do produto. Ciência Rural, 43(7), 1330-1336. 